\title{
AVALIAÇÃO DE MÉTODOS PARA OBTENÇÃO DE PROTEÍNAS RECOMBINANTES
}

Recebido: $12 / 06 / 2017$

\author{
SANTOS JUNIOR, Alceu Gonçalves dos ${ }^{1}$; \\ PIRAINE, Renan Eugênio Araújo ${ }^{2}$; \\ CUNHA, Rodrigo Casquero ${ }^{3}$; \\ NIZOLI, Leandro Quintana ${ }^{4}$; \\ ANDREOTTI, Renato ${ }^{5}$; \\ LEITE, Fábio Pereira Leivas ${ }^{6}$.
} Aceito: 02/09/2017

\begin{abstract}
${ }^{1}$ Doutorando, Programa de Pós-Graduação em Veterinária/UFPEL; ${ }^{2}$ Doutorando, Programa de Pós-Graduação em Biotecnologia/UFPEL; ${ }^{3}$ Pós-Doc, Programa de Pós-Graduação em Biotecnologia/UFPEL; ${ }^{4}$ Professor, Doutor, Faculdade de Veterinária/UFPEL; ${ }^{5}$ Doutor, Laboratório de Biologia Molecular do Carrapato, Embrapa Gado de Corte; ${ }^{6}$ Professor, Doutor, Curso de Biotecnologia/UFPEL.
\end{abstract}

\section{RESUMO}

A utilização de Pichia pastoris para a produção de proteínas recombinantes apresenta inúmeras vantagens que esse sistema agrega, destacando-se a exportação das moléculas para o meio extracelular. Isto permite que a obtenção das proteínas possa ser realizada por métodos de precipitação, com uso de sais neutros ou solventes orgânicos, sem trazer prejuízos. O objetivo deste trabalho foi avaliar a utilização de sulfato de amônio, acetona e metanol para obtenção da proteína recombinante Bm86 do carrapato Rhipicephalus microplus expressa por $P$. pastoris. A ação provocada pelos solventes orgânicos ocasionou uma solubilidade parcial das proteínas. Na quantificação por densitometria da proteína $\mathrm{rBm86}-\mathrm{CG}$, verificou-se que utilizando acetona (1:2) foi obtido $30,3 \mathrm{mg} / \mathrm{L}$, metanol (1:2) $60,5 \mathrm{mg} / \mathrm{L}$ e com sulfato de amônio a $70 \%$ (83,5 mg/L). A manutenção das características antigênicas após a precipitação foi verificada pela técnica de Western Blot, sendo que a proteína rBm86-CG obtida pelos três métodos foi reconhecida por anticorpos específicos. Os resultados sugerem que a precipitação com sais neutros e solventes orgânicos pode ser utilizada para obtenção de proteínas recombinantes como a rBm86-CG, sem trazer prejuízos a sua antigenicidade.

Palavras-chave: Pichia pastoris. Sais neutros. Solventes orgânicos. Antigenicidade. 


\section{INTRODUÇÃO}

O uso da levedura metilotrófica Pichia pastoris para a produção de proteínas recombinantes oferece uma série de vantagens sobre outros sistemas de expressão eucariótico, sistemas mais complexos, como em células de insetos e de mamíferos (CREGG et al., 2000). Entre as vantagens, destaca-se: capacidade de atingir rapidamente elevada densidade celular, possuir uma ampla variedade de vetores para manipulação genética, realizar a exportação de proteínas recombinantes para o meio extracelular e o fato de realizar modificações póstraducionais (MACAULEY-PATRICK et al., 2005).

A exportação de proteínas recombinantes para o meio extracelular faz com que $P$. pastoris disponibilize de forma solúvel a proteína produzida, o que facilita a sua obtenção e permite o uso de alternativas na purificação (MACAULEY-PATRICK et al., 2005). A precipitação de proteínas é um dos métodos de purificação rotineiramente explorado, pois apresenta baixo custo, reduz o volume da amostra e possui fácil aplicabilidade (JAHIC et al., 2006). Além disso, tem a finalidade de clarificar as amostras, para em uma segunda etapa ser empregada em processos cromatográficos (DUONG-LY; GABELLI, 2014).

A precipitação de proteínas tem sido estudada principalmente com o uso de sais neutros, tais como cloreto de sódio $(\mathrm{NaCl})$, sulfato de sódio $\left(\mathrm{N}_{2} \mathrm{SO}_{4}\right)$ e mais frequentemente usado é o sulfato de amônio $\left(\mathrm{NH}_{4}\right)_{2} \mathrm{SO}_{4}$ (DOONAN, 2004). Os solventes orgânicos também podem ser empregados para precipitação e concentração de proteínas (GRODZKI; BERENSTEIN, 2010), tais como metanol, etanol, butanol e mais comumente utilizada é a acetona, na preparação de amostras de proteínas para a análise de proteômica, como espectrometria de massas (SIMPSON; BEYNON, 2010).

Cada grupo possui um mecanismo de ação para precipitação das proteínas; os sais neutros promovem uma redução na concentração ideal de água superficial, levando à precipitação conhecida por "salting out" (DUONG-LY; GABELLI, 2014); enquanto que os solventes orgânicos, através de seus grupos polares, interagem com os grupos polares da proteína, presentes na superfície e região intramolecular de maneira a impedir a hidratação, resultando na redução da solubilidade e precipitação proteica (TSCHELIESSNIG et al., 2014). 
O emprego da precipitação é uma alternativa na obtenção de proteínas recombinantes, seja com o uso de sais ou solventes orgânicos, permitindo a obtenção das proteínas de forma simplificada (JAHIC et al., 2006). Entretanto, é conveniente verificar se as propriedades antigênicas foram preservadas no final do processo (SIMPSON; BEYNON, 2010).

O objetivo do presente estudo foi avaliar a obtenção da proteína recombinante $\mathrm{Bm} 86$ de Rhipicephalus microplus (rBm86-CG) expressa em $P$. pastoris utilizando o sal neutro sulfato de amônio e os solventes orgânicos, acetona e metanol.

\section{MATERIAL E MÉTODOS}

\section{Expressão da proteína rBm86-CG}

Para expressão de rBm86-CG em P. pastoris foi utilizada a metodologia descrita por Cunha et al. (2012). Para tal, clones resultantes da transformação por eletroporação da cepa GS115 Mut $^{+}$de P. pastoris contendo o plasmídeo pPiczaA/Bm86-CG foram cultivados em meio Buffered Glycerol Complex Medium (BMGY - extrato de levedura 1\%; peptona 2\%; fosfato de potássio 100 mM; YNB 1,34\%; biotina 4,10-5\%; glicerol 1\%; pH 6,0), por 24 h, em agitador orbital $(150 \mathrm{rpm})$, a $30{ }^{\circ} \mathrm{C}$. O cultivo com D. $0.600 \mathrm{~nm} 4$ foi centrifugado a $3.300 \times \mathrm{g}$, por 5 minutos. O pellet de células obtido foi suspenso em meio Buffered Methanol Complex Medium (BMMY - extrato de levedura 1\%; peptona 2\%; fosfato de potássio $100 \mathrm{mM}$; YNB 1,34\%; biotina 4,10-5\%; metanol 0,5\%; pH 6,0), e mantido a $30{ }^{\circ} \mathrm{C}$, sob agitação. Posteriormente, o cultivo obtido foi induzido com metanol 1\%, a cada 24 horas. Após 96 horas, o cultivo foi centrifugado a $3.300 \times \mathrm{g}$ por 5 minutos e o sobrenadante separado, adicionado de $100 \mathrm{mM}$ de Phenylmethylsulfonyl fluoride (PMSF - Sigma-Aldrich) e mantido a $-20{ }^{\circ} \mathrm{C}$, até a sua utilização.

Alíquotas de $10 \mathrm{~mL}$ do sobrenadante receberam a adição de acetona e metanol (Vetec), nas proporções 1:1, 1:2 e 1:3 (sobrenadante/solvente), respectivamente, e sulfato de amônio (Symth), nas concentrações de 25\%, 35\%, 55\%, 60\%, 65\%, 70\%, 75\% e 80\%, conforme relatado por Englard e Sam (1990). Após, os sobrenadantes foram incubados à $4{ }^{\circ} \mathrm{C}$ por $3 \mathrm{~h}$ e centrifugados a $8.000 \times \mathrm{g}$, por 5 minutos. Os precipitados foram solubilizados em $1 \mathrm{~mL}$ de 
solução a $50 \mathrm{mM}$ de Tris- $\mathrm{HCl}$ pH 7,0, contendo $100 \mathrm{mM}$ de PMSF, e armazenados a $-20{ }^{\circ} \mathrm{C}$ até a sua análise.

\section{Quantificação da proteína rBm86-CG}

Os precipitados obtidos a partir do cultivo foram suspensos em tampão de amostra (glicerol $10 \%, \beta$-mercaptoetanol 5\%, SDS 2,3\%, Tris- $\mathrm{HCl}$ pH 6,8 0,0625 M), aquecidos a $50{ }^{\circ} \mathrm{C}$ por 8 minutos e submetidos à eletroforese em gel de poliacrilamida (SDS-PAGE) 7,5\%, a $100 \mathrm{~V}$ por 90 minutos. O gel obtido foi corado com Coomassie Blue R-250 (Bio-Rad). As imagens foram analisadas e quantificadas por densitometria, com auxílio do software TotalLab 2.0 (Amersham/Biosciences).

\section{Western Blot}

As frações que obtiveram maior concentração da proteína rBm86-CG foram submetidas a eletroforese em gel de poliacrilamida $15 \%$ e eletrotransferidas para membrana de nitrocelulose HybondTM ECL (GE Healthcare). Após o bloqueio (PBS-T, 5\% leite em pó desnatado), a membrana foi lavada em solução PBS-T e incubada por $1 \mathrm{~h}$, a $37^{\circ} \mathrm{C}$, com um pool de soros bovinos vacinados com vacina comercial contendo a proteína rBm86 (1:400). Foi realizada nova lavagem em PBS-T e o anticorpo secundário anti-bovino (1:5000, conjugado com horseradish peroxidase, HRP, Sigma-Aldrich) foi adicionado, incubando-se por 1 hora a $37^{\circ} \mathrm{C}$. A reação foi revelada com solução contendo 3,3'- Diaminobenzidina (0,6 mg 3,3'- Diaminobenzidina (DAB) - Sigma-Aldrich; sulfato de níquel 0,03\%, tris-HCl $50 \mathrm{mM}$ pH 8,0 - Synth; peróxido de hidrogênio 30 v/v - Synth).

\section{RESULTADOS E DISCUSSÃO}

\section{Precipitação}

O sobrenadante contendo a proteína $\mathrm{rBm86-CG}$, ao ser adicionado com os solventes orgânicos (acetona e metanol), apresentou uma reação instantânea de precipitação. Ao aumentar a proporção do solvente em relação ao sobrenadante, ocorreu o aumento do precipitado (Figura 1). 

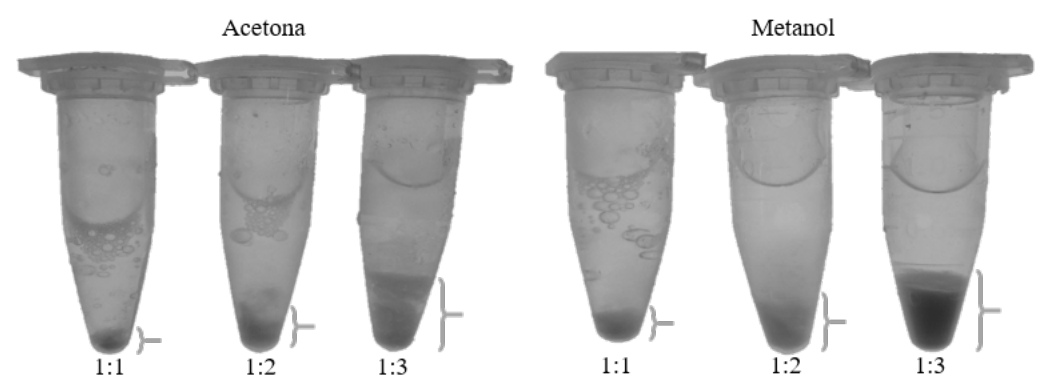

Figura1 - Precipitações de rBm86-CG por acetona e metanol. A figura mostra os precipitados nas proporções de 1:1, 1:2 e 1:3 do sobrenadante/solvente.

Na Figura 1 é possível visualizar que tanto a acetona quanto o metanol formaram um precipitado insolúvel em todas as frações. Observou-se que, com o aumento da concentração no gradiente agente precipitante/proteína, houve uma maior precipitação de proteínas. Com o uso de tampão $50 \mathrm{mM}$ Tris- $\mathrm{HCl}$ para solubilização das proteínas, foi evidenciado que as amostras precipitadas com acetona e metanol foram solubilizadas parcialmente, permanecendo uma porção insolúvel (Figura 1).

As proteínas solubilizadas em Tris- $\mathrm{HCl}(50 \mathrm{mM})$ e precipitadas, podem ser visualizadas na Figura 2. Identificou-se que na fração 1:2 o metanol apresentou uma obtenção superior a acetona, cerca de $60,5 \mathrm{mg} / \mathrm{L}$ de proteína solúvel, enquanto que a acetona obteve $30,3 \mathrm{mg} / \mathrm{L}$, quando quantificado por densitometria pelo software TotalLab 2.0.

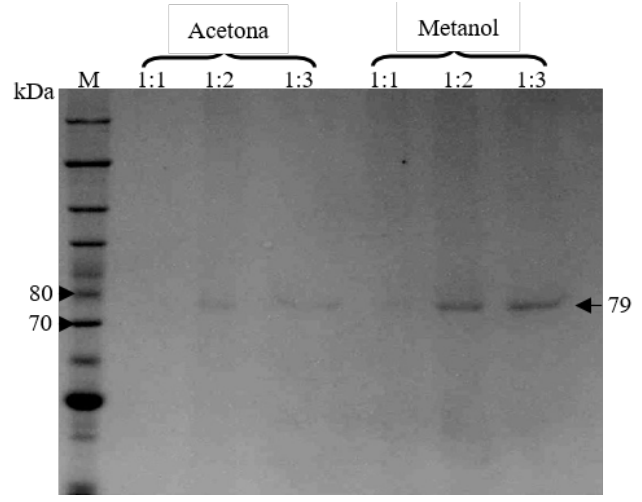

Figura 2 - SDS-PAGE 15\% para análise da obtenção da proteína rBm86-CG (79 kDa) precipitada por acetona e metanol. M - BenchMark ${ }^{\mathrm{TM}}$ Protein Ladder standard; precipitações com acetona e metanol na proporção de sobrenadante/solvente. 


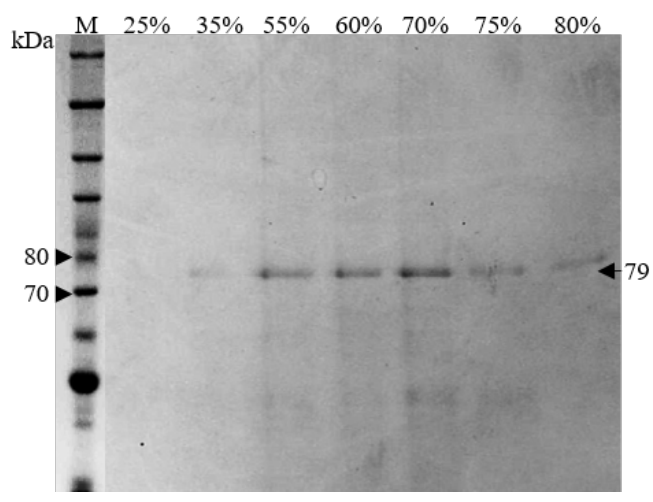

Figura 3 - SDS-PAGE 15\% para análise da obtenção da proteína rBm86-CG (79 kDa) precipitada com sulfato de amônio. M - BenchMark ${ }^{\mathrm{TM}}$ Protein Ladder standard; gradiente de precipitação (p/v) de 25 a 80\%.

A rBm86-CG precipitada por sulfato de amônio foi completamente solubilizada no tampão Tris-HCl, na Figura 3 é possível identificar a obtenção da rBm86-CG a partir da concentração 35\% até $80 \%$. Na quantificação do gradiente de precipitação de rBm86-CG utilizando sulfato de amônio, através do software TotalLab 2.0 , observou-se que a fração $70 \%$ evidenciou a melhor obtenção, cerca de $83,5 \mathrm{mg} / \mathrm{L}$ da proteína.

\section{Western Blot}

No Western Blot, os anticorpos de bovinos produzidos a partir da inoculação de uma vacina comercial contendo Bm86 reconheceram a rBm86-CG obtida das precipitações. Utilizando a concentração de $5 \mu \mathrm{g}$ de cada precipitação, observou-se que aquelas produzidas pelos solventes apresentaram uma reação de menor intensidade em comparação ao sulfato de amônio, como pode ser observado na Figura 4.

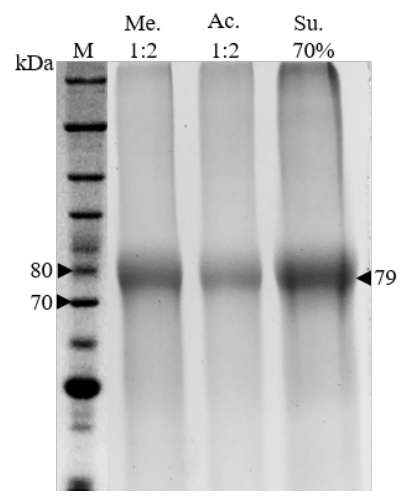

Figura 4 - Western Blot da reatividade de rBm86-CG (79 kDa) com anticorpos de bovinos, após obtenção das precipitações. M - BenchMark ${ }^{\mathrm{TM}}$ Protein Ladder standard; Me. - obtenção com metanol (1:2); Ac. - obtenção com acetona (1:2); Su. - obtenção com sulfato de amônio (70\%). 
A busca por métodos de obtenção de proteínas secretadas no sobrenadante de cultivos de P. pastoris tem auxiliado na otimização de produção e etapas de purificação (JAHIC et al., 2006).

O sulfato de amônio tem sido empregado como primeira escolha na obtenção de proteínas recombinantes expressas por $P$. pastoris, e os resultados têm demonstrado que sua utilização na concentração entre $70-80 \%$ tem permitido a maior obtenção de proteínas em diferentes estudos (DUMMER et al., 2009; HARTWIG et al., 2010; NIZOLI et al., 2009). Raramente são reportados estudos que envolvem a análise do rendimento utilizando outros métodos de precipitação para mesma proteína (WERTEN et al., 2001).

A obtenção de rBm86-CG testando outros métodos de precipitação complementa estudos anteriores (CUNHA et al., 2012) e possibilita a investigação dos diferentes agentes de precipitação e seu rendimento na obtenção de proteínas recombinantes.

Entre os métodos de obtenção de proteínas, observou-se que ao utilizar solventes orgânicos e/ou sais neutros, encontramos resultados diferentes na obtenção de rBm86-CG. O gradiente de precipitação utilizando sulfato de amônio permitiu a separação de frações contendo impurezas, como descrito por Duong-Ly e Gabelli (2014), e obtenção do melhor rendimento na obtenção de rBm86-CG $(83,5 \mathrm{mg} / \mathrm{L})$ com $70 \%$ de sulfato de amônio. Os resultados apresentados são semelhantes aos obtidos por Mohammed et al. (2017), que ao utilizarem o sulfato de amônio em gradiente, conseguiram remover grande parte das impurezas nas primeiras frações e obter, em seguida, frações com alta pureza.

A obtenção da rBm86-CG obtida neste estudo, utilizando o sulfato de amônio (70\%) foi $25 \%$ superior ao reportado por Cunha et al. (2012), que utilizaram o metanol, sugerindo que o uso do sulfato de amônio é uma alternativa a ser considerada na obtenção da rBm86-CG. O rendimento superior obtido pela precipitação com sulfato de amônio pode ser explicado pela solubilização parcial das proteínas precipitadas com os solventes orgânicos (Figura 1). Esta observação sugere que a reação intramolecular promovida pela acetona e metanol tenha provocado alterações na proteína, dificultando a sua solubilidade (TSCHELIESSNIG et al., 2014). Werten et al. (1999) reportaram o uso de gradiente em precipitações com acetona para remover proteínas mais instáveis, e obter a proteína com maior pureza em 
concentrações superiores, como $80 \%$ v/v, sem problemas de solubilidade. Entretanto, a ação causada pela acetona pode ter comprometido a solubilidade de rBm86-CG, além disso é possível que outras proteínas mais instáveis tenham sido precipitadas em conjunto, o que dificulta a solubilização (WERTEN et al., 1999). Isto poderia explicar a baixa solubilidade da rBm86-CG precipitada por acetona, resultando na menor obtenção, 30,3 mg/L neste estudo.

O emprego do metanol na precipitação, geralmente é utilizado em estudos de farmacocinética, como por exemplo, na precipitação experimental de saponina entre componentes plasmáticos (WANG et al., 2015). Sendo também amplamente utilizado para precipitação de proteínas presentes no plasma sanguíneo de animais e humanos (SUN et al., 2016). Entretanto, neste estudo a ação causada na precipitação por metanol trouxe perda da solubilidade de rBm86-CG (Figura 1). A obtenção da proteína utilizando metanol $(60,5 \mathrm{mg} / \mathrm{L}$ ) é semelhante a alcançada por Cunha et al. (2012), de 62,5 mg/L.

Evidencia-se que a obtenção das precipitações por solventes orgânicos teve uma solubilização parcial de rBm86-CG. Uma tentativa para aumentar a solubilização dos precipitados seria a utilização de um tampão contendo a alta molaridade de um agente desnaturante, como a ureia, a qual poderia favorecer a solubilização (BURGESS, 2009). Entretanto, isso incluiria também posteriores etapas de dessalinização, o que tornaria esta metodologia mais dispendiosa e de pouca usabilidade, além disso, toda vantagem de obtenção da proteína solúvel estaria sendo deixada de lado (CREGG et al., 2000).

A utilização de solventes orgânicos na precipitação de proteínas recombinantes exige cautela (DOONAN, 2004). A interação promovida por solventes orgânicos pode provocar uma reação irreversível na proteína precipitada, não sendo mais possível sua solubilização, havendo dessa forma prejuízos em sua utilização e sua função (TSCHELIESSNIG et al., 2014).

Demonstrou-se que apesar da solubilidade parcial de rBm86-CG precipitada com solventes orgânicos, a proteína recuperada foi capaz de ser reconhecida por anticorpos específicos, sugerindo que manteve regiões antigênicas comuns preservadas (Figura 4).

A rBm86-CG recuperada com sulfato de amônio foi eficientemente solubilizada no tampão Tris $\mathrm{HCl} 50 \mathrm{mM}$ (Figura 3) e também foi reconhecida por anticorpos específicos. Wang et al. (2013) destacaram a importância da utilização de sulfato de amônio, uma vez que a 
instabilidade e precipitação promovida pelo sal geralmente traz menores riscos à perda das propriedades proteicas. Neste sentido, cabe salientar que a reação de anticorpos bovinos específicos evidenciou uma maior reatividade à rBm86-CG obtida com sulfato de amônio em comparação a acetona e metanol. Além disso, a precipitação por sulfato de amônio permite que a amostra seja concentrada e submetida à purificação por cromatografia sem prejuízos a sua imunogenicidade (JEONG et al., 2016; KWON, 2012; Ll et al., 2015; MA, 2013).

O uso de diferentes métodos de precipitação é uma importante ferramenta que pode otimizar processos e minimizar custos de produção, entretanto é importante que os mesmos sejam avaliados para cada proteína separadamente, investigando se suas propriedades de interesse foram preservadas.

\section{CONCLUSÃO}

Com base nos resultados, conclui-se que os processos de precipitação com sais neutros e solventes orgânicos realizados permitiram a obtenção da rBm86-CG, preservando sua antigenicidade, sendo o sulfato de amônio o mais eficiente na obtenção e solubilização da proteína, obtendo cerca $83,5 \mathrm{mg} / \mathrm{L}$. Esses resultados encorajam estudos semelhantes com outras moléculas de importância industrial, com o objetivo de diminuir custos e tornar mais simples o processo e a purificação.

\section{EVALUATION OF METHODS FOR OBTAINING RECOMBINANT PROTEINS}

\section{ABSTRACT}

T

he use of Pichia pastoris for the production of recombinant proteins presents numerous advantages, especially the export of the molecules to the extracellular medium. This allows the protein to be obtained by precipitation methods, with the use of neutral salts or organic solvents, without detriment. The objective of this work was to evaluate the use of ammonium sulfate, acetone and methanol to obtain the recombinant Bm86 protein of the Rhipicephalus microplus tick expressed by $P$. pastoris. The action of the organic solvents caused a partial solubility of the proteins. In the quantification, by densitometry, of the $\mathrm{rBm} 86-\mathrm{CG}$ protein, it was found that using acetone (1:2) it was obtained $30.3 \mathrm{mg} / \mathrm{L}$, methanol (1:2) $60.5 \mathrm{mg} / \mathrm{L}$ and ammonium sulfate $70 \%$ ( $83.5 \mathrm{mg} / \mathrm{L}$ ). The maintenance of the antigenic characteristics after the precipitation was verified by the 
Western Blot technique, and the rBm86-CG protein obtained by the three methods was recognized by specific antibodies. The results suggest that the precipitation with neutral salts and organic solvents can be used to obtain recombinant proteins such as rBm86-CG, without impairing its antigenicity.

Keywords: Pichia pastoris. Neutral salts. Organic solvents. Antigenicity.

\section{EVALUACIÓN DE MÉTODOS PARA OBTENCIÓN DE PROTEÍNAS RECOMBINANTES}

\section{RESUMEN}

a utilización de Pichia pastoris para la producción de proteínas recombinantes presenta innumerables ventajas que ese sistema agrega, destacándose la exportación de las moléculas hacia el medio extracelular. Esto permite que la obtención de las proteínas pueda ser realizada por métodos de precipitación, con uso de sales neutras o solventes orgánicos, sin traer perjuicios. El objetivo de este trabajo fue evaluar la utilización de sulfato de amonio, acetona y metanol para obtener la proteína recombinante Bm86 de la garrapata Rhipicephalus microplus expresada por $P$. pastoris. La acción provocada por los disolventes orgánicos ocasionó una solubilidad parcial de las proteínas. En la cuantificación por densitometría de la proteína $\mathrm{rBm86}-\mathrm{CG}$, se verificó que utilizando acetona (1:2) se obtuvo $30,3 \mathrm{mg} / \mathrm{L}$, metanol (1:2) $60,5 \mathrm{mg} / \mathrm{L}$ y con sulfato de amonio al $70 \%$ (83,5 mg/L). El mantenimiento de las características antigénicas después de la precipitación fue verificado por la técnica de Western Blot, siendo que la proteína rBm86-CG obtenida por los tres métodos fue reconocida por anticuerpos específicos. Los resultados sugieren que la precipitación con sales neutras y disolventes orgánicos puede ser utilizadas para la obtención de proteínas recombinantes como la $\mathrm{rBm86-CG}$, sin traer perjuicios a su antigenicidad.

Palabras clave: Pichia pastoris. Sales neutras. Solventes orgánicos. Antigenicidad.

\section{REFERÊNCIAS}

BURGESS, R. R. Chapter 17 refolding solubilized inclusion body proteins. Methods in Enzymology, v. 463, p. 259-282, 2009.

CUNHA, R. C.; PÉREZ DE LEÓN, A. A.; LEITE, F. P. L.; et al. Bovine immunoprotection against Rhipicephalus (Boophilus) microplus with recombinant Bm86-Campo Grande antigen.

Revista Brasileira de Parasitologia Veterinária, v. 21, n. 3, p. 254-262, 2012. 
DOONAN, S. Bulk purification by fractional precipitation. Methods in molecular biology, $\mathrm{v}$. 244, p. 117-24, 2004.

DUMMER, L. A.; CONCEIÇÃO, F. R.; NIZOLI, L. Q.; et al. Cloning and expression of a truncated form of envelope glycoprotein D of Bovine herpesvirus type 5 in methylotrophic yeast Pichia pastoris. Journal of Virological Methods, v. 161, n. 1, p. 84-90, 2009.

DUONG-LY, K. C.; GABELLI, S. B. Salting out of proteins using ammonium sulfate precipitation. Methods in Enzymology, v. 541, p. 85-94, 2014.

ENGLARD, S.; SAM, S. Precipitation techniques. Methods in Enzymology, v. 182, p. 285-300, 1990.

CREGG, J. M.; CEREGHINO, J. L.; SHI, J.; HIGGINS, D. R. Recombinant protein expression in Pichia pastoris. Molecular Biotechnology, v. 16, n. 1, p. 23-52, 2000.

GRODZKI, A. C.; BERENSTEIN, E. Immunocytochemical methods and protocols. Journal of Chemical Information and Modeling, v. 588, p. 1689-1699, 2010.

HARTWIG, D. D.; OLIVEIRA, T. L.; SEIXAS, F. K.; et al. A High yield expression of leptospirosis vaccine candidates LigA and LipL32 in the methylotrophic yeast Pichia pastoris. Microbial cell factories, v. 9, n. 1, p. 98, 2010.

JAHIC, M.; VEIDE, A.; CHAROENRAT, T.; et al. Process technology for production and recovery of heterologous proteins with Pichia pastoris. Biotechnology Progress, v. 22, n. 6, p. 14651473, 2006.

JEONG, K. Y.; YI, M.; SON, M.; et al. IgE reactivity of recombinant pacc3 from the asian needle ant (Pachycondyla chinensis). International Archives of Allergy and Immunology, v. 169, n. 2, p. 93-100, 2016.

KWON, W. T. Protective immunity of Pichia pastoris expressed recombinant envelope protein of japanese encephalitis virus. Journal of Microbiology and Biotechnology, v. 22, n. 11, p. 1580-1587, 2012.

LI, J.; ZHU, W.; LUO, M.; et al. Molecular cloning, expression and purification of lactoferrin from tibetan sheep mammary gland using a yeast expression system. Protein Expression and Purification, v. 109, p. 35-39, 2015.

MACAULEY-PATRICK, S.; FAZENDA, M. L.; MCNEIL, B.; et al. Heterologous protein production using the Pichia pastoris expression system. Yeast, v. 22, n. 4, p. 249-270, 2005.

MA, J. Expression, purification and characterization of a recombinant Tat47-57-Oct4 fusion protein in Pichia pastoris. Molecular Medicine Reports, v. 9, n. 2, p. 471-475, 2013. 
MOHAMMED, S. A.; EISSA, M. S.; AHMED, H. M. Simple protein precipitation extraction technique followed by validated chromatographic method for linezolid analysis in real human plasma samples to study its pharmacokinetics. Journal of Chromatography. B, v. 1043, p. 235-240, 2017.

NIZOLI, L. Q.; CONCEIÇÃO, F. R.; SILVA, S. S.; et al. Immunogenicity and antigenicity of the recombinant EMA-1 protein of Theileria equi expressed in the yeast Pichia pastoris. Revista Brasileira de Parasitologia Veterinária, v. 18, n. 2, p. 1-4, 2009.

SIMPSON, D. M.; BEYNON, R. J. Acetone precipitation of proteins and the modification of peptides. Journal of Proteome Research, v. 9, p. 444-450, 2010.

SUN, Y.; XUE, J.; LI, B.; et al. Simultaneous quantification of triterpenoid saponins in rat plasma by UHPLC-MS/MS and its application to a pharmacokinetic study after oral total saponin of Aralia elata leaves. Journal of Separation Science, v. 39, p. 4360-4368, 2016.

TSCHELIESSNIG, A.; SATZER, P.; HAMMERSCHMIDT, N.; et al. Ethanol precipitation for purification of recombinant antibodies. Journal of Biotechnology, v. 188, p. 17-28, 2014.

WANG, F.; LI, X.; MO, X.; et al. A biologically active VMIP-II-IgG3-TfN fusion protein, secreted from methylotrophic yeast Pichia pastoris. Protein Expression and Purification, v. 87, n. 1, p. 47-54, 2013.

WANG, Z.; WU, Q.; MENG, Y.; et al. Determination and pharmacokinetic study of two triterpenoid saponins in rat plasma after oral administration of the extract of Aralia elata leaves by UHPLC-ESI-MS/MS. Journal of Chromatography B, v. 985, p. 164-171, 2015.

WERTEN, M. W. T.; VAN DEN BOSCH, T. J.; WIND, R. D.; et al. High-yield secretion of recombinant gelatins by Pichia pastoris. Yeast, v. 15, n. 11, p. 1087-1096, 1999.

WERTEN, M. W. T.; WISSELINK, W. H.; JANSEN-VAN DEN BOSCH, T. J.; et al. Secreted production of a custom-designed, highly hydrophilic gelatin in Pichia pastoris. Protein Engineering Design and Selection, v. 14, n. 6, p. 447-454, 2001

Autor para correspondência: 